doso en la 1

ar ejemplos a

is funcionalidac uso, dependiende encarnan los conceptos detr por e $\Lambda$ influ
$\mathrm{Pe}$ infin:

Las formas $d r$ oceso de sig ialidad .

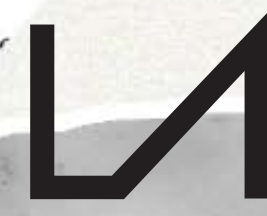

R E V I S A
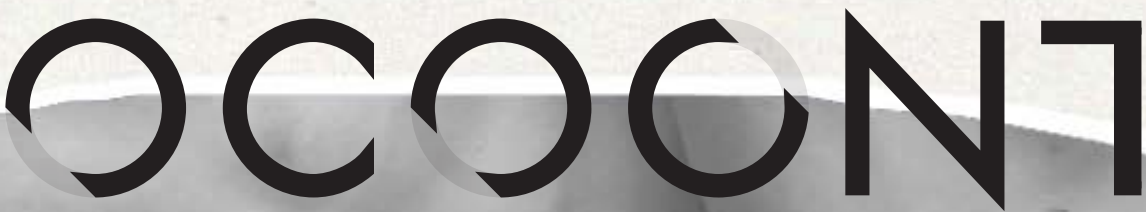

D $E$

No $6 \cdot 2019 \cdot$ ISSN 2386-8449

"El producto del diseñador es un proyecto, el estado previo de un objeto", Entrevista con Norberto Chaves, por Fernando Infante

El papel de la investigación y la teoría en diseño. Una conversación abierta, por Fernando Infante y María Jesús Godoy

UT PICTURA POESIS

Abandonar la escritura. Poesía experimental y manifiesta, Ignacio Gómez de Liaño

PANORAMA: FILOSOFÍA DEL DISEÑO Sección coordinada por Fernando Infante y María Jesús Godoy

Pensar el diseño, Fernando Infante y María Jesús Godoy (Coordinadores)

TEXTOS INVITADOS

Estatus y estado del điseño más allá del objeto, Pedro Medina Reinón

Mar de Nubes, Cuerpo de Cristal, Dionisio González

ARTÍCULOS

Understanding Design Aesthetics beyond Functional Beauty accounts, Lucía Jiménez Sánchez

Estética y diseño industrial: debates y controversias, Joan M. Marín

Del ornamento al delito. El diseño y la sociedad en Charles Baudelaire y Adolf Loos, Jorge López Lloret

When is Architecture not Design? Saul Fisher

Diseño y habitabilidad: una aproximación basada en los lenguajes de patrones, Antonio Hidalgo Pérez

Marcel Breuer: un diseñador global. Experiencias en el ámbito de la vivienda prefabricada, Salvador J. Sanchis, Ignacio Peris y Pedro Ponce Diseño y artes escénicas: el papel de Oskar Schlemmer en Das Triadische Ballett y la actualidad de la Bauhaus, Milagros García Vázquez Lo performativo en prácticas de arte y diseño actuales vinculadas a procesos de innovación social. El caso de La Venezia che non si vede y de La borda, Tània Costa Gomez

Articulaciones de la estética y el diseño. El caso de la evaluación a partir de la investigación dirigida en la carrera de diseño escénico de la Universidad de las Artes de Cuba, Mara Rodríguez Venegas y Xiomara Romero Rojas

SUPLEMENTO

El diseño, la ciudad y un lápiz de labios, Mercedes Espiau, Mar García Ranedo y Alejandro Rojas mas. 


\section{UつCつCNTE}

No $6 \cdot 2019 \cdot \operatorname{ISSN} 2386-8449 \cdot$ DOI 10.7203/LAOCOONTE.5.15381

https://ojs.uv.es/index.php/LAOCOONTE/index

COORDINACIÓN EDITORIAL

Anacleto Ferrer (Universitat de València)

Francesc Jesús Hernàndez i Dobon (Universitat de València)

Fernando Infante del Rosal (Universidad de Sevilla)

SECRETARÍA DE REDACCIÓN

Lurdes Valls Crespo (Universitat de València)

Vanessa Vidal Mayor (Universitat de València)

COMITÉ DE REDACCIÓN

Tamara Djermanović (Universitat Pompeu Fabra), Rosa Fernández Gómez (Universidad de Málaga), Anacleto Ferrer (Universitat de València), Ilia Galán (Universidad Carlos III), Ana María García Varas (Universidad de Zaragoza), María Jesús Godoy (Universidad de Sevilla), Fernando Infante del Rosal (Universidad de Sevilla), Miguel Ángel Rivero (Universidad de Sevilla), Miguel Salmerón (Universidad Autónoma de Madrid), Gerard Vilar (Universitat Autònoma de Barcelona).

COMITÉ CIENTÍFICO INTERNACIONAL

Rafael Argullol* (Universitat Pompeu Fabra), Luis Camnitzer (State University of New York), José Bragança de Miranda (Universidade Nova de Lisboa), Bruno Corà (Università di Cassino), Román de la Calle* (Universitat de València), Eberhard Geisler (Johannes Gutenberg-Universität Mainz), José Jiménez* (Universidad Autónoma de Madrid), Jacinto Lageira (Université Paris 1 Panthéon-Sorbonne), Bernard Marcadé (École Nationale Supérieure d'Arts de Paris-Cergy), Elena Oliveras (Universidad de Buenos Aires y Universidad del Salvador), Pablo Oyarzun (Universidad de Chile), Francisca Pérez Carreño* (Universidad de Murcia), Bernardo Pinto de Almeida (Faculdade de Belas Artes da Universidade do Porto), Luigi Russo (Università di Palermo), Georges Sebbag (Doctor en Filosofía e historiador del surrealismo), Zoltán Somhegyi (University of Sharjah, United Arab Emirates), Robert Wilkinson (Open University-Scotland), Martín Zubiria (Universidad Nacional de Cuyo). *Miembros de la Sociedad Española de Estética y Teoría de las Artes, SEyTA

\begin{tabular}{lll}
\hline DIRECCIÓN DE ARTE & REVISIÓN DE TEXTOS & TRANSCRIPCIÓN DE TEXTOS \\
El golpe. Cultura del entorno & Antonio Cuesta & Álvaro G. Serna
\end{tabular}

(cc) BY Excepto que se establezca de otra forma, el contenido de esta revista cuenta con una licencia Creative Commons Atribución 3.0 España, que puede consultarse en http://creativecommons.org/licenses/by/3.0/es/deed.es

EDITA

\section{SEyTA.}

CON LA COLABORACIÓN DE

\begin{tabular}{|c|c|c|c|}
\hline $\begin{array}{l}\text { VNIVERSITAT } \\
\text { B VALENCIA } \\
\text { Institut te Creativitat } \\
\text { | |nnovacions Educatives }\end{array}$ & $\begin{array}{l}\text { VNIVERSITAT } \\
\text { IE ÖVALENCIA Departament de Filosofia }\end{array}$ & 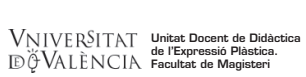 & \\
\hline $\begin{array}{l}\text { DEPARTAMENTO DE ESTÉTICA } \\
\text { E HISTORIA DE LA FLLOSOFIA }\end{array}$ & $\frac{\text { UAW }}{\frac{\text { UNIVRSSIDAD AUTONOMA }}{\text { DE MADRID }}}$ & $\begin{array}{l}\text { Universitat Autònoma } \\
\text { de Barcelona }\end{array}$ & $\begin{array}{l}\text { VNiVERSiDAD } \\
\text { Departamento de Filosofia, Lógica y Estética }\end{array}$ \\
\hline
\end{tabular}

LAOCOONTE aparece en los catálogos: 


\section{LつCつCN7E}

"Cuanto más penetramos en una obra de arte más pensamientos suscita ella en nosotros, y cuantos más pensamientos suscite tanto más debemos creer que estamos penetrando en ella".

G. E. Lessing, Laocoonte o los límites entre la pintura y la poesía, 1766.

Vo hay cól.

létodo, de pen.

:ión en general. Ith

zar la forma para el $\mathrm{n}$.

eptual por las orígenes

la, el objeto, la exposición

storia, porque existe en el $\mathrm{m}$

das sus raíces. Desde alli cc _. panoram

n conceptual y donde el émencia del con 'iseñado, como es el a al objeto y el di $\begin{array}{ll}\text { igen } \mathrm{de}^{\text {to }} \text { la inmer } & \text { tolvidada, o comc } \\ \text { trozo de madera ar }\end{array}$ a manera dorm comunicar ene nundo. Seguin? sngo en manos te el método $C$ les. A partir c teria prima $\mathrm{p}_{\mathbf{c}}$

'xto se puede:

¿ño, en proyea

amientos de $\mathrm{u}$

a conscie-

.)

en la publicación jue "plos de la impor te las nalidades porqu ura un ${ }^{2}$ diendo de qui zenerar $\mathrm{u}$ ción de nr? lne

in-

n-

is.

le http:,

le crear visualidades. A partir de.

ellas la propia materia prima para un en que desde un texto se puede generar $u_{11}$ i

Pensar en diseño, en proyección de nue

posibles comportamientos de una colecti

presente como una consciencia del hecho que estamos elaborando, significac

nuestro entorno (..)

Cardoso, R. C. Rafael. (2014). Design para um mundo complexo. Sãc asil: Cosac Naify. 


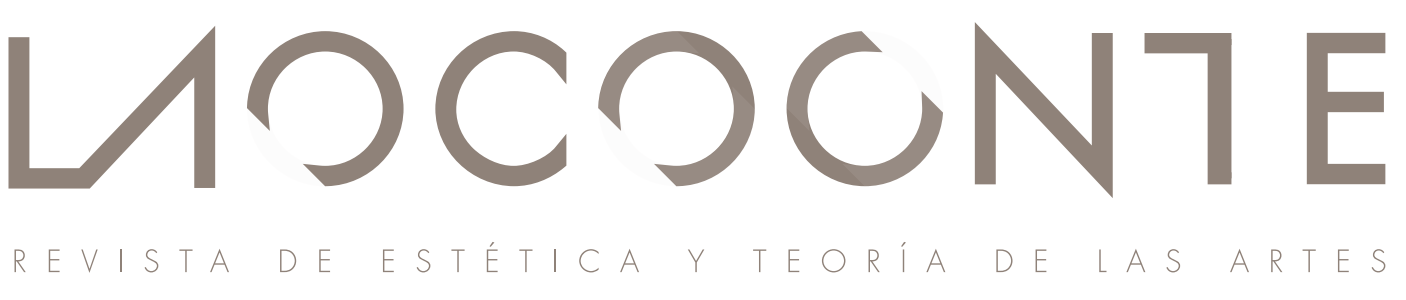

$\mathrm{N}^{\circ} 6 \cdot 2019$

PRESENTACIÓN

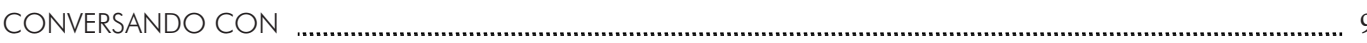

"El producto del diseñador es un proyecto, el estado previo de un objeto", Entrevista con Norberto Chaves,

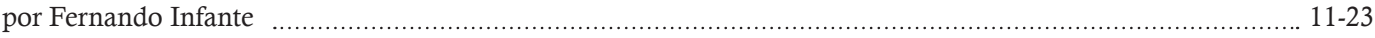

El papel de la investigación y la teoría en diseño. Una conversación abierta, por Fernando Infante

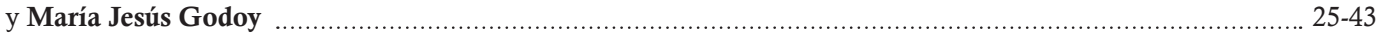

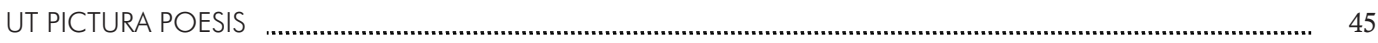

Abandonar la escritura. Poesía experimental y manifiesta, Ignacio Gómez de Liaño ................................................ 47-95

Imágenes de Laocoonte n. 6, de Isadora Gonzaga ................................................................................................... 96-97

PANORAMA

FILOSOFÍA DEL DISEÑO

Pensar el diseño, Fernando Infante y María Jesús Godoy (Coordinadores) .............................................. 101-105

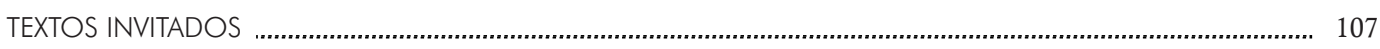

Estatus y estado del diseño más allá del objeto, Pedro Medina Reinón . ................................................... 109-125

Mar de Nubes. Cuerpo de Cristal, Dionisio González .............................................................................. 127-133

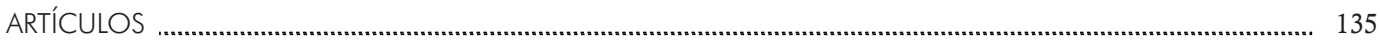

Understanding Design Aesthetics beyond Functional Beauty accounts, Lucía Jiménez Sánchez ................. 137-149

Estética y diseño industrial: debates y controversias, Joan M. Marín _...................................................... 150-164

Del ornamento al delito. El diseño y la sociedad en Charles Baudelaire y Adolf Loos, Jorge López Lloret ... $165-182$

When is Architecture not Design? Saul Fisher ……............................................................................. 183-198

Diseño y habitabilidad: una aproximación basada en los lenguajes de patrones, Antonio Hidalgo Pérez ...... 199-215

Marcel Breuer: un diseñador global. Experiencias en el ámbito de la vivienda prefabricada,

Salvador José Sanchis, Ignacio Peris y Pedro Ponce

Diseño y artes escénicas: el papel de Oskar Schlemmer en Das Triadische Ballett y la actualidad de la Bauhaus, Milagros García Vázquez

Lo performativo en prácticas de arte y diseño actuales vinculadas a procesos de innovación social.

El caso de La Venezia che non si vede y de La borda, Tània Costa Gomez

Articulaciones de la estética y el diseño. El caso de la evaluación a partir de la investigación dirigida en la carrera de diseño escénico de la Universidad de las Artes de Cuba, Mara Rodríguez Venegas

y Xiomara Romero Rojas

SUPLEMENTO 
Walter Gropius. La vida del fundador de la Bauhaus, Jorge Martínez Alcaide

¿Qué significa pensar la política desde la estética? Àger Pérez Casanovas

Ideologías estéticas en los orígenes de la pintura moderna, José Luis Plaza Chillón 300-303

Sobre a estética, Luis Carlos Pereira

Músicas populares. Sociedad y territorio: Sinergias entre investigación y docencia, Mar Aleixandre Badenes.

307-309

La necesidad de la mirada antropológica sobre la literatura, Pablo de Benito David

A propósito de Chandler, o la novela policíaca como tratado filosófico, Juan Evaristo Valls Boix

Videre aude!, Anacleto Ferrer

La inaplazable memoria del dolor y el sufrimiento, Antonio Notario Ruiz

La alargada sombra de la pintura, Raquel Baixauli

Sondear la maravilla, Juan Evaristo Valls Boix

... Y lo sabes, Marc Hernández Montoro

Arqueologías de la modernidad en las artes. Ensayo estético, Carlota Fernández-Jáuregui Rojas

Estética de la Instalación, Luis Cemillán Casis

La Herencia de otra época, María Jesús Godoy Domínguez

Del Theatrum Mundi al Gran Vidrio, Miguel Salmerón Infante

Imágenes de Isadora Gonzaga.

Fotografía de portada de Tamara Djermanovic intervenida por Isadora Gonzaga.

Los coordinadores de la sección Panorama: Filosofia del diseño agradecen

a Antonio Molina Flores su colaboración. 


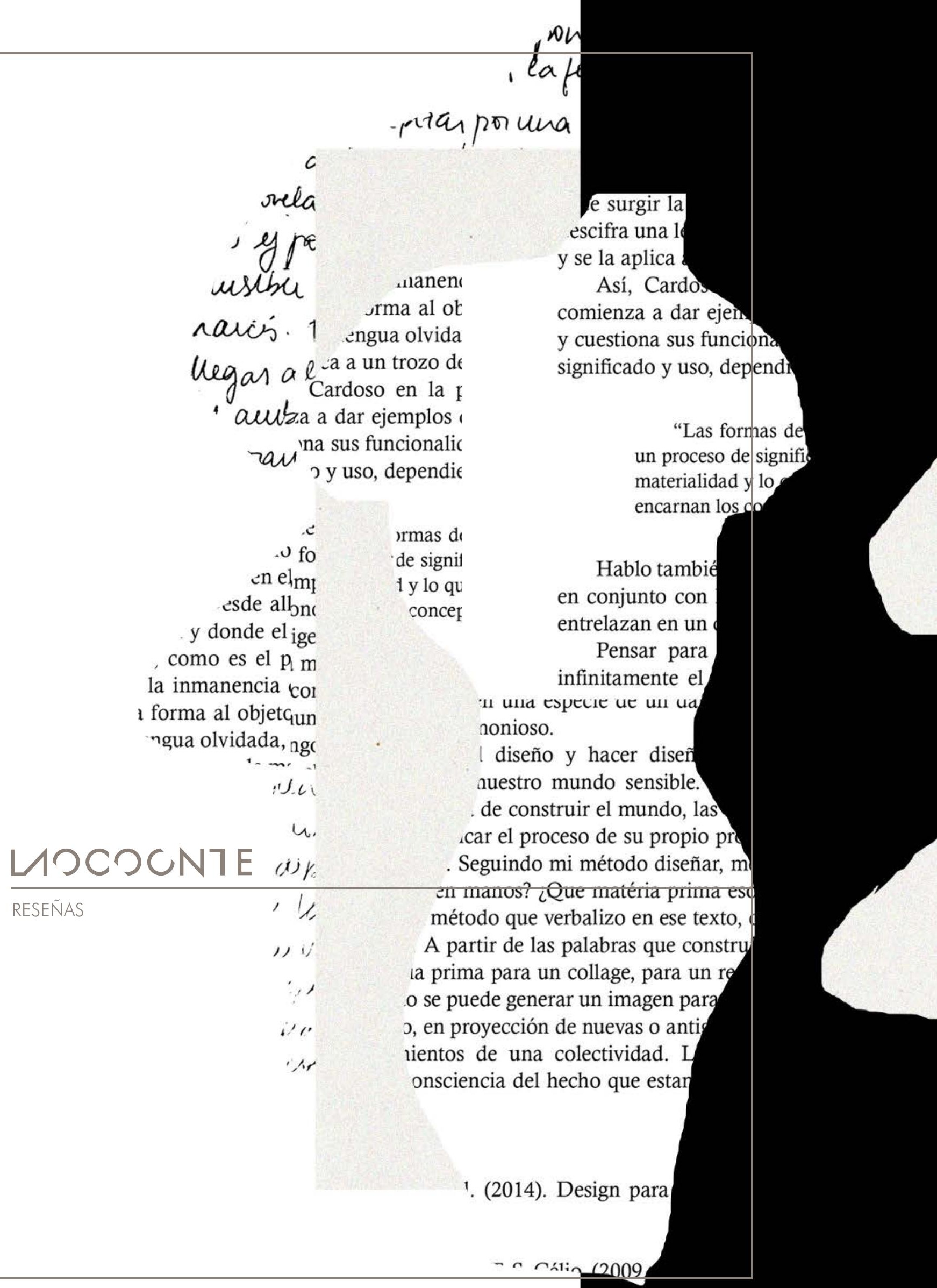




\title{
La inaplazable memoria del dolor y el sufrimiento
}

\author{
Antonio Notario Ruiz*
}

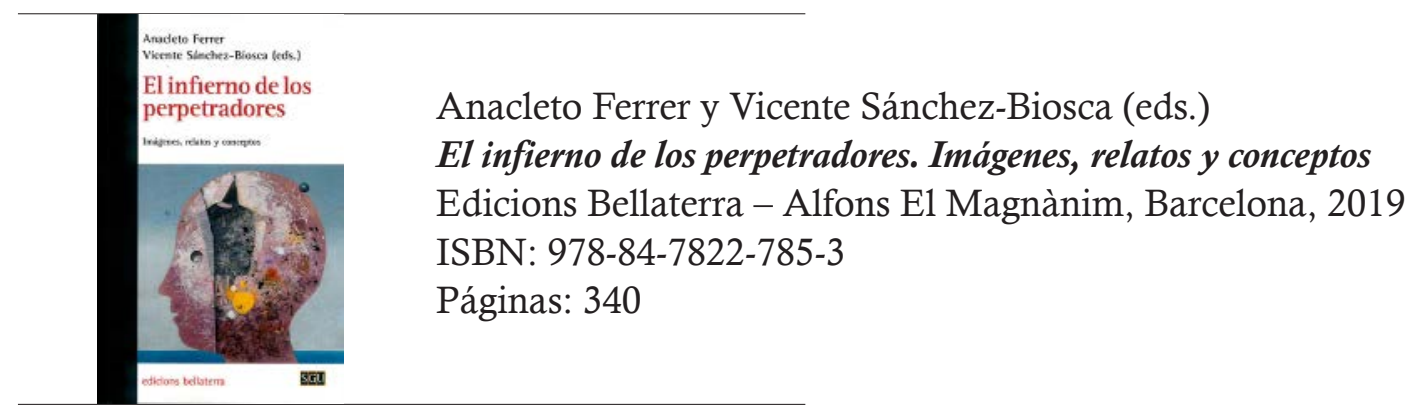

En los compases finales de la Segunda Guerra Mundial, antes de que se conociera por completo la magnitud alcanzada por la voluntad criminal del nazismo, los filósofos Adorno y Horkheimer, entre otros, habían comenzado a llamar la atención sobre las víctimas. Lo hacían desde la filosofía y desde ese paradigma naciente entonces, la Teoría Crítica. Otras voces encontraban expresión para sus experiencias o las de amistades, familiares y vecinos a través de la literatura, como en el caso de Anna Seghers (La séptima cruz, 1939 y La excursión de las muchas muertas, 1943). Aunque había precedentes en los textos de la Escuela de Salamanca-Francisco de Vitoria, Bartolomé de las Casas, Domingo de Soto, Fray Juan Ramírez de Arellano y otros muchos autores-, se configura en los textos de los filósofos francfortianos una categorización de las víctimas como protagonistas de la etapa de terror desatada por los totalitarismos pero también de cara al futuro, encarnándose en los supervivientes. Las presentan como un nuevo sujeto de la historia y no como mera consecuencia de conflictos y guerras. En el momento inicial de la posguerra, tras la liberación de los campos de concentración y de exterminio, surgió la otra ocupación y preocupación: la de buscar a los verdugos y juzgarlos, aunque con escaso éxito penal. Víctimas, supervivientes y verdugos marcan la mayor parte de las teorizaciones y de los relatos hasta el célebre juicio de Eichmann en 1961. Es a partir de ese momento, gracias sobre todo a la cobertura de Hannah Arendt y a sus propuestas teóricas a partir de las declaraciones del nazi, cuando se contempla de frente uno de los problemas subyacentes al asesinato masivo fríamente organizado: el problema del mal en una doble vertiente: como tema central y global, por una parte, y en su individuación en cada uno de los actores que ejecutaron los planes asesinos, por otra. Fueron emergiendo entonces otras preguntas: ¿quiénes asesinaron, torturaron o vejaron a las víctimas? ¿Cómo actuaron? ¿Por qué? Y la gran pregunta, ya indicada también por Adorno sobre la transformación en asesinos, torturadores y violadores de personas que vivían vidas anodinas, normales: ganz normale Männer. Esa

* Universidad de Salamanca, España.anotaz@usal.es 
cuestión es clave para abordar el intento de no repetir esa barbarie.

En esa problemática se inserta esta publicación que solo puede calificarse como acertada, muy bien documentada y recomendable para quienes investiguen en un amplio abanico de disciplinas, desde la historia a la filosofía, la psicología a la teoría de la comunicación, la sociología a la estética, la fotografía al cine y, sin duda, a las personas que investigan en la historia contemporánea de España. La categoría de perpetrador se había tenido en cuenta en el ámbito de la psicología pero aplicada de forma preferente a los casos de violencia doméstica, escolar o de espacios sociales reducidos y en el campo de la criminología. Pero desde los años ochenta del siglo XX ha comenzado su uso en las investigaciones sobre los asesinatos masivos cometidos tanto por diferentes regímenes totalitarios como en conflictos recientes -la guerra en los países balcánicos que formaban la República Federal Popular de Yugoslavia o los conflictos étnicos de Ruanda-. Y desde comienzos de este siglo ha ido emergiendo el uso de esta categoría vinculada con las responsabilidades individuales en los crímenes colectivos: la del perpetrador y como extensión inevitable, los actos de la perpetración. Los investigadores que colaboran en este libro desarrollan diferentes perspectivas, incorporando el ámbito castellanoparlante así a un campo de estudio novedoso pero que ya tiene un cierto recorrido en otras tradiciones como la alemana y la anglosajona.

Han sido Anacleto Ferrer y Vicente Sánchez-Biosca quienes han reunido y editado en este libro doce ensayos, precedidos por una Introducción, alcanzando una densidad asfixiante y angustiosa tanto por el contenido estético y ético como por la profundidad con que se afronta en cada uno de ellos la tarea adorniana de intentar conocer el cómo y el porqué de los comportamientos de diferentes perpetradores de la historia reciente. Desde puntos de vista diversos, utilizando diferente documentación de los campos nazis de exterminio, los asesinatos en Camboya o el sadismo de miembros de las tropas estadounidenses en Irak, un denominador común parece perfilarse en diferentes actividades, en diferentes contextos, sin distinción de sexos o de cualquier otro tipo: la del placer de la mirada que se recrea en la propia obra y tarea de aniquilamiento del otro, obra y tarea que no es fácil dudar que también proporcionaba placer a los perpetradores en algún nivel. Ferrer y Sánchez-Biosca han asumido la propuesta adorniana, planteada en los años sesenta y se han unido con esta publicación a la que podemos denominar como tradición investigadora abierta por Raul Hilberg en 1961, solo que ampliando el campo de estudio a diferentes procesos de destrucción sistematizada del otro.

Entre las muchas fortalezas de este libro no es la menor la incorporación al panorama español de la investigación en un ámbito de problemas que, lejos de estar circunscrito al pasado, sigue vigente. Perpetradores y perpetradoras actúan con facilidad hoy como ayer sin que las sociedades actuales acierten a encontrar la forma de evitarlo. Fuera del foco de esta publicación se puede pensar en los muy recientes casos de la persecución de la minoría rohinyá en Myanmar o en las peligrosas derivas que se perciben en algunos países africanos y asiáticos. También cabría una continuidad de la investigación dirigida a la esfera cotidiana, no por más cercana y reducida menos preocupante que las grandes matanzas burocratizadas o no del siglo XX, en la que se va produciendo día a día esa tragedia que nadie parece ser capaz de detener: los asesinatos de mujeres a manos de sus parejas o exparejas.

El libro que reseño es una obra coral vinculada a un proyecto de investigación que recoge las voces de doce personas, todas ellas relevantes en este campo de investigación 
por trabajos anteriores. El libro está estructurado en una introducción a cargo de los editores y tres partes. La primera recoge los trabajos de Gabriel Gatti (Universidad del País Vasco) que reflexiona sobre las víctimas; el ensayo de Cristina García Pascual (Universidad de Valencia) sobre los perpetradores; y el de Benno Herzog (Universidad de Valencia), ocupado en los mecanismos de silenciamiento e invisibilización. La segunda parte recoge los ensayos de Jesús Casquete (Universidad del País Vasco) sobre las vinculaciones de una parte de la iglesia protestante con la violencia nazi; el de Arturo Lorenzo Aguilar (ULL) sobre algunos aspectos de la película Shoah de Claude Lanzmann; el de Jaume Peris Blanes (Universidad de Valencia) sobre algunas experiencias de la violencia en la dictadura chilena y sus consecuencias; el de Daniela Jara (Universidad de Valparaíso) sobre las representaciones de los perpetradores en la posdictadura chilena. La Tercera Parte reúne el ensayo de Anacleto Ferrer (Universidad de Valencia) que se ocupa de cuatro testimonio fotográficos del Holocausto; el de Rafael R. Tranche (Universidad Complutense) que recupera testimonios y reflexiones en torno a la liberación del campo de Bergen-Belsen; el de Alberto Sucasas (Universidad de A Coruña) que se centra en el victimario; el de Susanne C. Knittel (Universidad de Utrecht) que profundiza en los mecanismo de repetición, reenactment y representación en casos diferentes; y, cerrando el libro, el ensayo de Vicente Sánchez-Biosca (Universidad de Valencia) sobre diferentes vivencias asociadas a los actos de perpetración y sus implicaciones éticas y psicológicas. Cada uno de los ensayos, muy bien documentados en general, aporta elementos para la reflexión, en especial sobre el asesinato masivo organizado por el nazismo, aunque haya también dos ensayos centrados en la violencia asesina desatada en el Chile de la dictadura y en otros se mencionen las matanzas de los jémeres rojos en Camboya o los comportamientos sádicos de personal militar estadounidense en Irak. En muchos de los ensayos se presentan conclusiones pero también preguntas y problemas que quedan abiertos, facilitando el ejercicio crítico para los potenciales lectores.

Sería prolijo reseñar cada uno de los textos por extenso o incluso brevemente, por lo que propongo una selección que, dirigidos hacia objetivos diferentes, sirvan como visión panorámica del libro. Comenzando con Arturo Lozano Aguilar (135-153), se ocupa de uno de los protagonistas de la película de Claude Lanzmann Shoah: uno de los verdugos de Treblinka que ya había sido entrevistado en 1974 por Gitta Sereny. Esta duplicidad de fuentes permite a Lozano Aguilar contrastar la evolución de enfoques históricos entre los años setenta y ochenta. Pero le permite, sobre todo, mostrar la pericia de Lanzmann en su intento por encontrar al verdugo más allá del personaje creado a lo largo de los años y que había conseguido convencer a Gitta Sereny sobre la fiabilidad de su testimonio.

Jaume Peris Blanes afronta en su ensayo (155-175), uno de los más relevantes del libro en mi opinión, varios testimonios de protagonistas de la violencia asesina ejercida por la dictadura chilena. Una parte de esos testimonios se encuentran recogidos en documentales y textos más o menos novelados, aparte de entrevistas de diferente tipo. A diferencia de otros casos estudiados en este libro, en Chile se dio la circunstancia de que algunas personas pasaran de víctimas a verdugos. El que más ocupa a Peris Blanes es el de Alejandra Merino, militante del MIR que acaba colaborando con la DINA tras ser torturada salvajemente por ésta. Lo narra ella misma en el documental dirigido por la compañera de uno de los militantes asesinados por la DINA, Carmen Castillo. Aparece un problema ético y psicológico peculiar puesto que el paso de la 
protagonista del documental -y no solo de ella- de víctima a perpetradora fue el precio de su supervivencia.

Anacleto Ferrer (191-223) ha elegido cuatro ejemplos fotográficos para su reflexión, lo que permite cierta continuidad en la lectura de su ensayo con el de Rafael R. Tranche. Aunque sean cuatro los conjuntos fotográficos elegidos, Ferrer los relaciona con otras fotografías y con algunos documentales y películas. Pero es preciso subrayar el marco teórico que explicita Ferrer antes de analizar las imágenes. Un marco sustentado por Benjamin y Kracauer que le lleva a afirmar que

[1]as imágenes y los conceptos, la representación visual y lingüística, la aprehensión y la comprensión desde la estética y la historia son el haz y el envés de una misma voluntad de apropiación de lo acontecido y de enunciación del acontecimiento no siempre exenta de desajustes (192).

El texto de Rafael R. Tranche se centra en las imágenes del descubrimiento y liberación de Bergen-Belsen, que han acabado dando lugar a un proyecto cinematográfico que no se ha podido ver en su integridad y en el montaje previsto por su inspirador, Sidney Bernstein, hasta el año 2014. La gran variedad de registros tanto fotográficos como filmados y sonoros, la variedad de 'voces' visuales permitieron que se acumulara un archivo que no ha existido en otros casos. Y ese archivo precipita en el documental que no consiguió ver Bernstein pero que ahora puede producir en quienes lo vean la conmoción que Sontag contó que le habían producido las fotografías de la liberación del campo de Bergen-Belsen. Pero el autor plantea una cuestión central que atañe a estas y a todas las imágenes que se comentan en este libro: ¿Cuál es la utilidad de las mismas más allá de "horrorizarnos una vez pasado su momento genésico"? Y él mismo contesta que el visionado de todas estas imágenes convierten al espectador en testigo, "depositario de su transmisión, pero al tiempo le condenan, como a la mujer de Lot, a quedar atrapado en la escena sospechoso de su inacción” (250).

El capítulo que cierra el libro es el escrito por Vicente Sánchez-Biosca (297-337). Se centra en el análisis de imágenes de perpetradores que, a la vez que documentos de barbarie, y tal vez en tanto que tales, se convierten en perpetradoras. Combina análisis de dato de la Segunda Guerra Mundial, de imágenes filmadas del gueto de Varsovia, fotografías de la Camboya aterrorizada por Pol Pot y de los abusos contra los presos por parte de personal militar estadounidense en la segunda guerra del Golfo. Unas y otras le llevan a concluir la dualidad de las imágenes de perpetradores: "constituyen un enigma y un velo" (335), "nacen de una pasión enfermiza, un goce, infligen sufrimiento y lo prolongan en su condición de archivo documental (334).

Memoria y aviso, por lo tanto, más que en cualquier otro texto sobre los diferentes desbordamientos asesinos desde Auschwitz. La filosofía, en la mayoría de sus ramificaciones posibles, no debería contribuir a la desmemoria que se procura desde diferentes centros de poder en la actualidad. Por eso esta publicación ha de servir en debates filosóficos, en la docencia de estética, de ética, de filosofía política tanto como en debates de antropología, de comunicación audiovisual o de sociología. Y sin perder de vista que la documentación audiovisual puede seguir creciendo en relación con esas u otras atrocidades pasadas, presentes o futuras. A la vez, este trabajo contribuye de forma excepcional a avisar sobre las condiciones todavía presentes de construcción de personas dispuestas a perpetrar, da igual si una violación grupal de mujeres a manos de lo que se ha dado en denominar como "manadas", un asesinato de una mujer sin techo en un cajero automático, o palizas mortales a los seguidores rivales de un equipo de fútbol. 
La herencia del dolor y el sufrimiento que nos deja la historia no ha cesado de crecer. Las figuras de la maldad, sus diferentes encarnaciones adquieren una doble presencia gracias a la potencia de la visualidad mecánica o digital. Adquieren también una nueva violencia que no es solo representación de los actos de perpetración. Y no son solo pasado. Lo que Claussen ${ }^{1}$ ha denominado como el imperativo categórico adorniano sigue vigente: organizar el pensamiento y la acción de modo que Auschwitz no se repita de ninguna forma y en ningún nivel. 


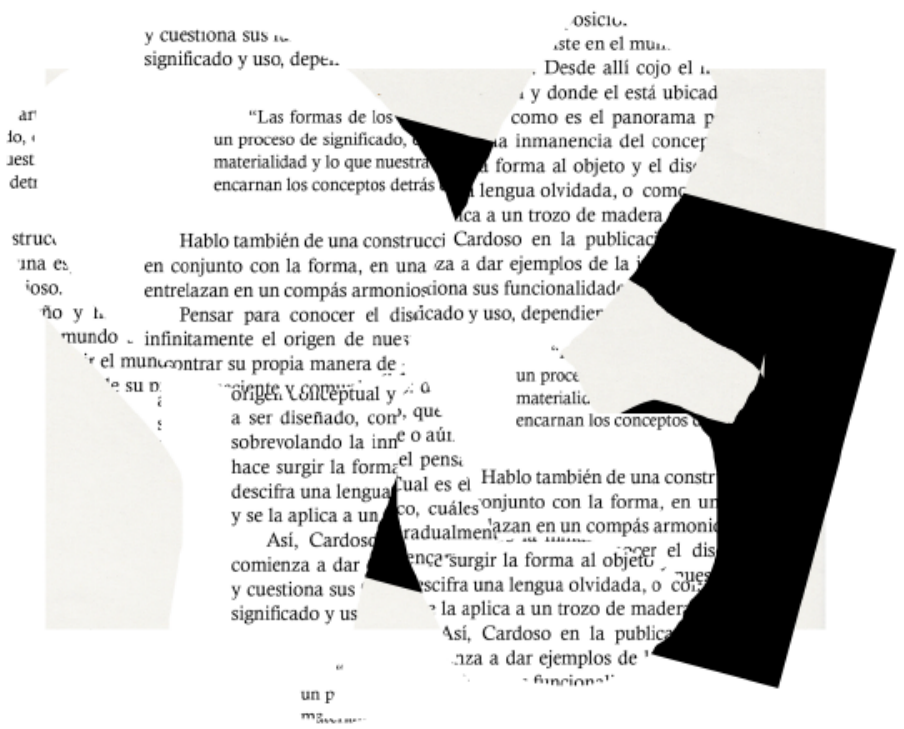

"Lo impreso exige una humildad de espíritu por cuya falta muchas de las bellas artes se tambalean ahora en experimentos de autoconciencia y sensiblería. No hay nada simple ni aburrido en lograr una página transparente. La ostentación vulgar es el doble de fácil que la disciplina".

Beatrice Warde, The Crystal Goblet, or why printings should be invisible (1930)

"El diseño que es objetivo, comprometido con el bien común, bien compuesto y delicado, constituye la base del comportamiento democrático".

Josef Müller-Brockmann, Grid and Design Philosophy (1981) 

EDITA

\section{SEyTA.}

SOCIEDAD ESPAÑLAA
DE ESTETICA Y TEORIA DE LAS ARTES

CON LA COLABORACIÓN DE

\begin{tabular}{|c|c|c|}
\hline 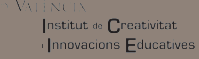 & $\begin{array}{l}\text { VNIVIRSIIA } \\
\text { In VVIIINCI Departament de Filosofia }\end{array}$ & 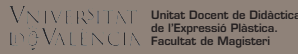 \\
\hline $\begin{array}{l}\text { TitTicA } \\
\text { SoFFA }\end{array}$ & 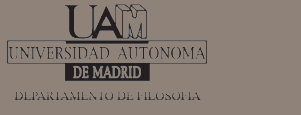 & $\begin{array}{l}\text { UAB } \\
\text { Universitat Autònoma } \\
\text { de Barcelona }\end{array}$ \\
\hline
\end{tabular}

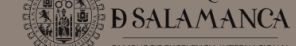

https://ojs.uv.es/index.php/LAOCOONTE/index 